\title{
SizeBR - The Brazilian Study on Anthropometric
}

\author{
Sergio FERREIRA BASTOS, Flávio SABRA, Rynaldo ROSA, Luis FELIPE \\ SENAI CETIQT, Rio de Janeiro, Brazil \\ http://dx.doi.org/10.15221/13.243
}

\begin{abstract}
In order to standardize and guide the clothing manufacturers in developing products to meet the textile and apparel chain, hence the construction of the gradations and modeling clothing in relation to standards bodies, Senai CETIQT, in 2006, began, still incipient, the mapping of different configurations of bodies Brazilians. Over those seven years, as the methodology was outlined and matured, the study of Senai CETIQT passed through several stages. First acquired tools for manual measurement and conducted a feasibility study with a small sample group comprised of students and staff of the institution itself. As the results were satisfactory, a new phase began with the acquisition of a body scanner and specialized services standardization of uniforms of the armed forces and auxiliaries. With the implemented methodology, it was possible a major step toward the anthropometric characteristics of the standard body of Brazilian design SizeBR. In 2010 Senai CETIQT listed the main consumption centers spread across five main regions: South, Southeast, Cento West, North and Northeast to start the first scientific study conducted by anthropometric scanning technology at the national level in order to behold the great dimensions of Brazil. Seeking greater breadth of research, the team of Innovation Management, Studies and Research through the line and Consumption Behavior of Senai CETIQT developed a questionnaire about consumption habits of Brazilians to be applied in conjunction with measurements to be obtained in these regions. For each consumption center, depending on the served population, we applied the statistical theory of sampling to define the number of Brazilians to be measured (the international standard ISO 15535:2012). So a specialized team consisting of technicians in the design, engineering, anthropology, social sciences, electronics and ergonomics was trained to go into the field and perform automatic measurements manuals and treat the images obtained by body scanners. Currently the project team SizeBR dedicated to the completion of the measurements and the statistical treatment of the data and has the forecast finalization of the national stage for males and females between 18 and 65 years and consequently Senai CETIQT. Continuing expansion SizeBR seeking to meet the other segments, Senai CETIQT is acquiring two more body scanners, one for feet and hands and another for head, in this way to meet with that segment of the field of Fashion.
\end{abstract}

Keywords: Anthropometric Survey, 3D body scanning, modeling clothing, sizing systems

\section{Introduction}

The Senai CETIQT is an institution of more than 60 years, is acting solely in the service of the textile and clothing chain. Through their actions and activities related to industry, plus directions, studies and research conducted in partnership with $\mathrm{ABIT}, \mathrm{ABDI}, \mathrm{MDIC}, \mathrm{MCTI}$, companies, plus the contributions of the agents that operate in various sectors of this segment, the anthropometric Brazilian research was one of the most relevant items requested. The research began in 2006, with the approval of SGPE-0602 for structuring the Course of Technology in Apparel Production, when it was acquired a body scanner to generate applied research and thus meet this market demand Brazilian. Through the project construction anthropometric survey, there was the beginning of it with the team structure, training, acquisition of current literature, translations, international survey of ongoing research, technologies used, physical structure among others to meet the research and technology course. After all surveys, analyzes and justifications made, the team began the process of acquiring and importing the body scanner technology of white light, in order that it could be transported more easily to the entire Brazilian territory. In parallel to the manual research and statistics guidelines to be adopted, and the team has constantly a flow through training to meet the diversity of research.

\footnotetext{
*sbastos1@gmail.com, fsabra@cetiqt.senai.br, rrosa@cetiqt.senai.br, lfbrito@cetiqt.senai.br
} 
In Brazil, the Brazilian Association of Technical Standards - ABNT is responsible for the dissemination of technical standards and standardization systems in general. Recently, more precisely in mid-2011, ABNT developed jointly with diverse stakeholders (Association of classes, educational institution, manufacturing industries and large retailers), the standard NBR16060: 2011 which defined and standardized a system of body sizes geared exclusively for making men's clothing. Throughout the year 2013 to ABNT is systematically gathering stakeholders in developing a technical standard to define a system of body size to meet the apparel for female clothing. Both technical standards that define the systems sizes of male and female bodies, were not developed from an anthropometric survey with a significant sample of the Brazilian population. The lack of standardization bodies of Brazilians causes a wide variation in the wearability of textile products from different brands and even the same brand. It is quite common to find in major retailers products of different sizes to suit one body, we can realize that there is a market practice to exchange label by companies cooking, so cater to the ego of consumers who do not accept his dummy and have consequently seek bigger clothes, but with smaller label. Thus, The Brazilian study on anthropometric - SizeBR seeks to answer the following questions: What is the body shape of the population? How many are the same way? What is the best segmentation of the population to develop a sizing system? How to relate the shape of the body with the system size? How to adjust the standard bodies in modeling clothing? What can be done so that the clothing manufacturers begin using the same system sizes? To answer these provocative questions, the Brazilian study on anthropometric - SizeBR priority in their lines of work, meet the following actions:

- Map the different biotypes male and female mannequins and generating tables updated measures;

- Develop a methodology for application of the results of measuring the human body, obtained from a sample survey;

- To systematize the information collected;

- Establish technical criteria for application of results;

- Structuring a methodology for building bases modeling, using the data collected;

- Create an experimental wearability laboratory;

- Develop mannequins with Brazilian standards, which will be tested in manufacturing companies, and may be used in the calibration bodyscanners;

- Develop standards for building the foundations of modeling;

- Develop standards for defining concepts of functionality and wearability;

- Provide the basis of data obtained in the project to other studies.

\section{Methodology}

To start the project characterization of the bodies of the population with a focus on wearability, Senai CETIQT acquired two Body Scanners White Light TC2. A team of five people was created to participate in the project of anthropometric measurements by regions of Brazil, the team consisted of an electronics technician, two physical education teachers, an expert in ergonomics and project manager. Each team member had a specific responsibility, namely: the manager was responsible for logistics system design and apply concepts of optimization and rationalization of information and material flow in the displacement of the team for the selected regions, the electronics technician by assembling and disassembling the body scanner and calibrate sensors, and monitor measurements for the case of some urgent maintenance, the physical education professionals to perform the measurements themselves and coach in ergonomics for maintaining the physical education teachers trained in the modus operandi measurements. The measurements were carried out as far as possible, according to the schedule defined in step displacement and logistics personnel. The team while receiving the volunteer in the measurement site, explained what was the project and its goals. After that the volunteer answered a socioeconomic questionnaire put the pieces of clothing suitable for measurements and headed for the body scanner to be measured. 
The body measurement data were treated by the staff directly in the software of the TC2 during the treatment was verified how the cloud of points, the landmarks, and occurred the removal of spurious data. The data after treatment were deposited in a database as specified in ISO 15535.

With the bank formed, it was possible to move to the statistical analysis and validation of the bodies. In this analysis we used the technique of principal components of the multivariate statistical table to set the standards bodies. Biotypes of brazilian women were defined based on a study prepared by Lee et al., 2007 [1] and will be disclosed in later works.

The final steps of the modeling study of items of clothing, testing parts in standard and non-standard bodies and validity of modeling developed in this study have not been included because the study is still in progress, counting only with the finalized data from the Southeast.

The methodology can be seen in Figure 1 below:

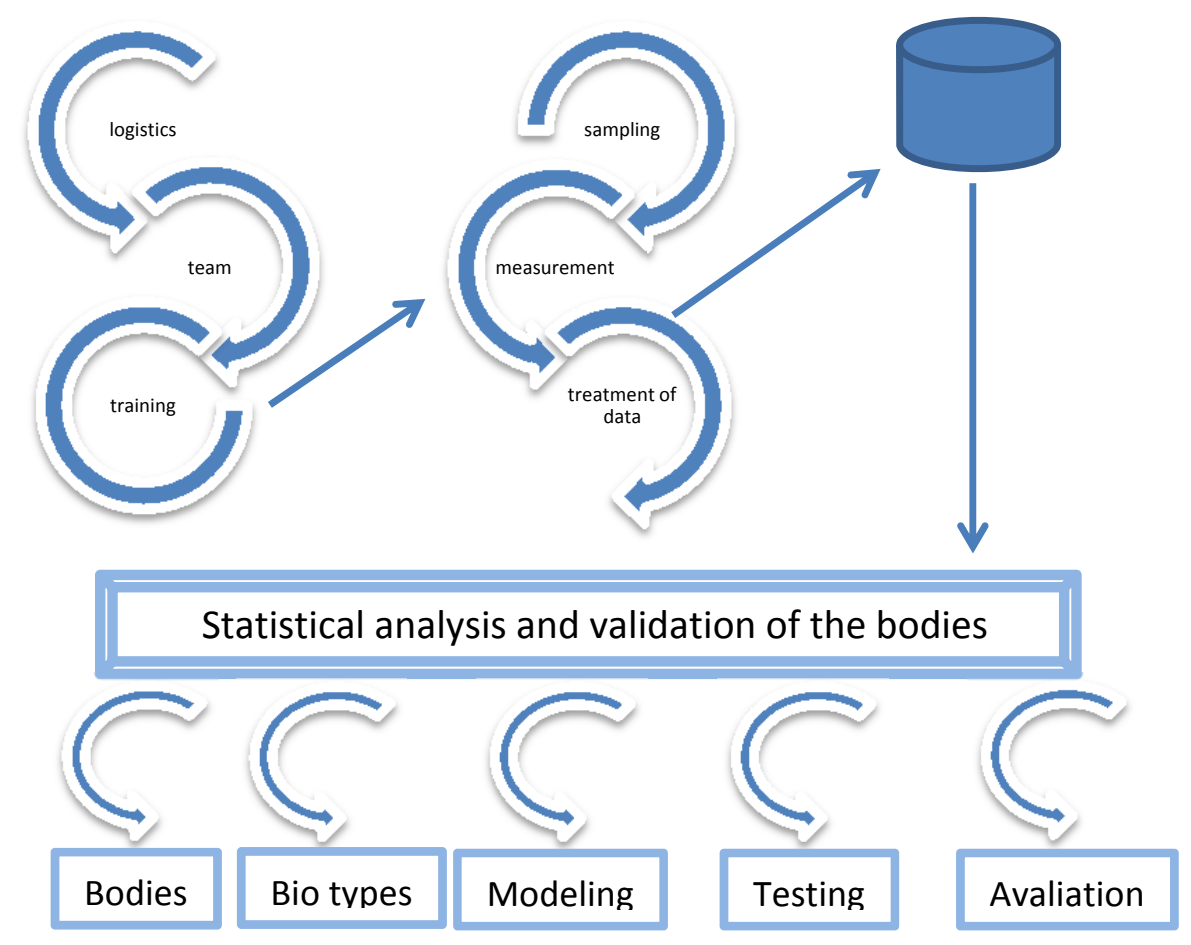

Fig 1. Methodology.

\subsection{Sampling}

Initially by having no body measurements of the sample population, it was decided to conduct a sampling as described in Thompson 2012 [3]. The sample size was calculated for the main regions of Brazil, ranked matches by major cities due to its position consumption. A search on the basis of the Brazilian Geographical and Statistical Institute - IBGE was performed to determine the population of Brazil, of both sexes, aged between 18 and 59 years in these cities. Table 1 shows the data obtained in the calculations IBGE and initial sampling. 
Table 1. Sampling Search SizeBR.

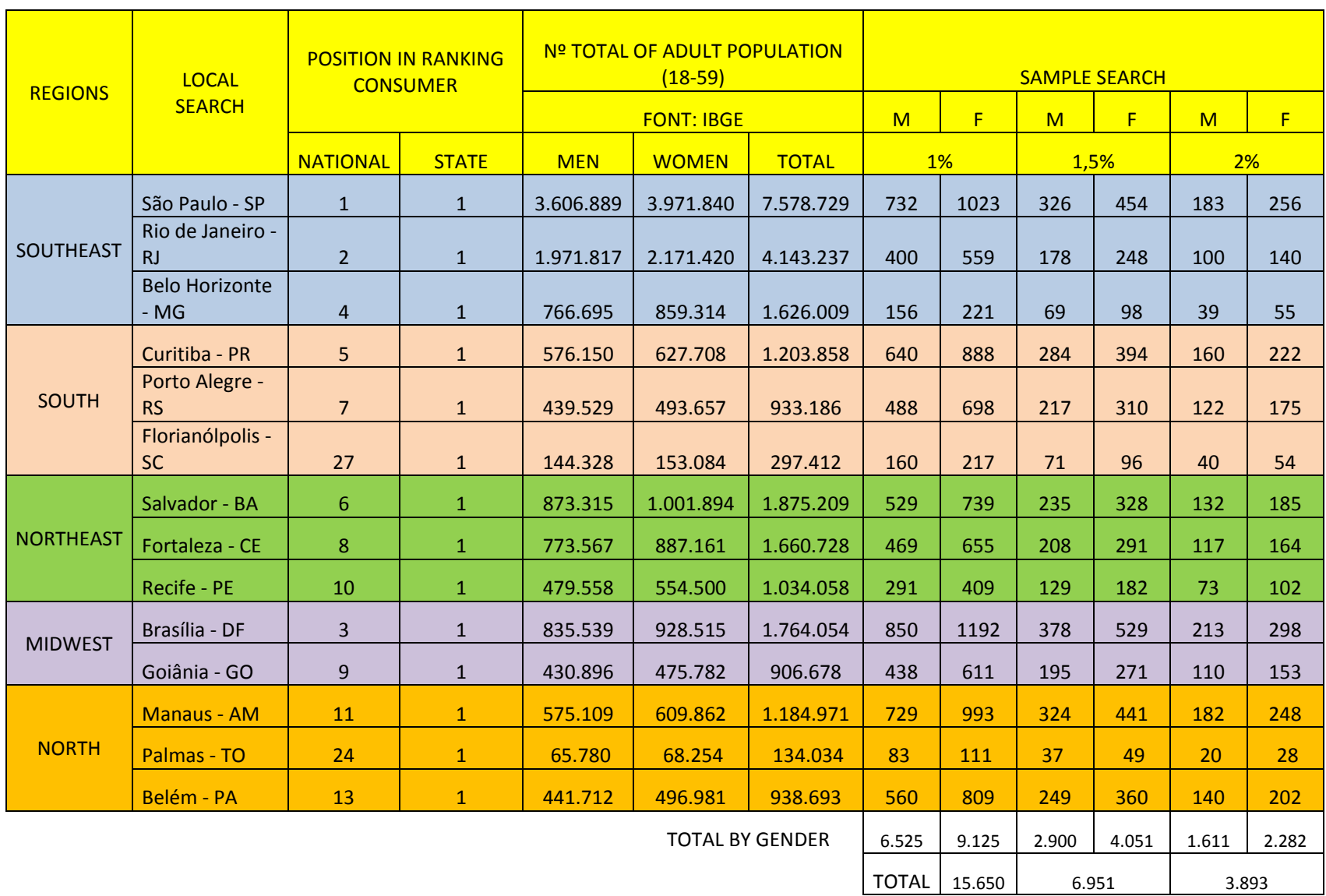

The Brazilian study on anthropometric- SizeBR - was initiated in southeastern Brazil. This region was chosen due to its proximity to Senai CETIQT, allowing rapid movements of the Body Scanner and study staff, namely the region permitted an easy logistics implementation.

After some measurements in the cities of Rio de Janeiro, Sao Paulo and Belo Horizonte the initial sampling established was recalculated to meet the established standard ISO 15535.

With the measurements it was possible to calculate the coefficient of variation - CV - the main measures to characterize the body of the Brazilian.

According to ISO 15535, it is necessary to calculate the minimum number of samples (via a small sample basis as before) that presents value of the variable with the highest coefficient of variation for this variable will request a higher number of samples, which will supply all the data involved in this kind of research.

The number of sample being measured takes into account a $95 \%$ confidence on the measurement error determined by the investigator using the following equation:

$$
\mathrm{N}=\left(\frac{1.96 \mathrm{CV}}{\mathrm{a}}\right)^{2} \cdot 1.534^{2}
$$

Being:

$\mathrm{N}=$ number of samples required;

$1.96=$ critical value of $z$, representing $95 \%$ confidence;

$\mathrm{CV}=$ coefficient of variation is determined by the following equation: 


$$
\mathrm{CV}=\frac{\mathrm{SD}}{\overline{\mathrm{x}}} \cdot 100
$$

Being:

$\mathrm{SD}=$ standard deviation;

$x^{-}=$Average

$a=$ the relative error to what you want

With these parameters we can calculate the necessary quantity to be measured to an error of $1 \%$, $1.5 \%$ and $2 \%$, by measuring the whole body as shown in table 2 . In that table it can be seen that for both genders as they showed higher coefficient of variation was waist circumference, and therefore the variable that defines the sampling minimum required to represent, with a prescribed error and $95 \%$ confidence, the Brazilian population. Thus, the sampling table by region was corrected to the value pointed to 1260 males and 1662 females for an error rate of $1 \%$, see Table 3 .

Table 2. Sampling and errors associated.

\begin{tabular}{|c|c|c|c|c|c|c|c|c|c|c|c|c|c|}
\hline \multicolumn{14}{|c|}{ Sampling error of the measured variables } \\
\hline \multirow[b]{2}{*}{ № } & \multirow{2}{*}{ measured variables } & \multicolumn{2}{|c|}{ Average } & \multicolumn{2}{|c|}{$\begin{array}{l}\text { Standard } \\
\text { Deviation }\end{array}$} & \multicolumn{2}{|l|}{ cv } & \multicolumn{2}{|c|}{ Error of $1 \%$} & \multicolumn{2}{|c|}{ Error of $1.5 \%$} & \multicolumn{2}{|c|}{ Error of $\mathbf{2 \%}$} \\
\hline & & $M$ & $\mathbf{F}$ & $M$ & $F$ & $M$ & $\mathbf{F}$ & $M$ & $F$ & $M$ & $F$ & $M$ & $F$ \\
\hline 409 & Waist Circumference & 91.5 & 84.8 & 10.8 & 11.5 & 11.8 & 13.6 & 1260 & 1662 & 560 & 739 & 315 & 416 \\
\hline 407 & Thorax circumference & 103.0 & 96.3 & 9.3 & 10.4 & 9.0 & 10.8 & 740 & 1059 & 329 & 471 & 185 & 265 \\
\hline 416 & Circumference of Hips & 99.9 & 101.8 & 7.5 & 9.5 & 7.5 & 9.3 & 508 & 782 & 226 & 348 & 127 & 196 \\
\hline 002 & stature & 174.4 & 162.0 & 6.9 & 6.4 & 3.9 & 4.0 & 141 & 144 & 63 & 64 & 36 & 36 \\
\hline 106 & Height of the crotch & 77.4 & 73.5 & 4.7 & 5.1 & 6.1 & 6.9 & 338 & 431 & 150 & 192 & 85 & 108 \\
\hline 117 & Height Waist Pelvis & 29.1 & 24.6 & 2.3 & 3.2 & 7.9 & 13.0 & 557 & 1539 & 247 & 684 & 139 & 385 \\
\hline 301 & Length Front View & 40.6 & 38.7 & 4.1 & 3.4 & 10.2 & 8.8 & 944 & 703 & 420 & 313 & 236 & 176 \\
\hline 302 & Length Rear View & 48.3 & 43.0 & 4.0 & 3.1 & 8.3 & 7.2 & 628 & 472 & 279 & 210 & 157 & 118 \\
\hline 113 & Height Waist Solo & 104.7 & 98.0 & 5.9 & 5.1 & 5.7 & 5.2 & 292 & 249 & 130 & 111 & 73 & 63 \\
\hline 124 & Height Knee Dir. & 48.4 & 44.3 & 2.9 & 3.0 & 5.9 & 6.9 & 315 & 426 & 140 & 190 & 79 & 107 \\
\hline 419 & Thigh circumference Dir & 58.8 & 59.8 & 5.4 & 7.0 & 9.2 & 11.7 & 758 & 1234 & 337 & 549 & 190 & 309 \\
\hline 300 & Cervical Solo Length & 169.0 & 156.7 & 7.1 & 6.5 & 4.2 & 4.1 & 162 & 154 & 72 & 69 & 41 & 39 \\
\hline 104 & Height Shoulder Dir & 141.3 & 130.7 & 6.6 & 5.9 & 4.7 & 4.5 & 196 & 187 & 87 & 83 & 49 & 47 \\
\hline 303 & $\begin{array}{l}\text { Front Shoulder Length Cross } \\
\text { Dir }\end{array}$ & 48.8 & 44.7 & 3.8 & 3.1 & 7.7 & 7.0 & 538 & 439 & 239 & 195 & 135 & 110 \\
\hline 304 & $\begin{array}{l}\text { Posterior Length Shoulder } \\
\text { Cross Dir }\end{array}$ & 48.9 & 43.2 & 3.3 & 2.8 & 6.8 & 6.4 & 420 & 373 & 187 & 166 & 105 & 94 \\
\hline 423 & Calf circumference Dir & 37.6 & 36.2 & 3.1 & 3.6 & 8.2 & 10.0 & 608 & 897 & 270 & 399 & 152 & 225 \\
\hline
\end{tabular}


Table 3. Sampling and errors associated with region of Brazil.

\begin{tabular}{|c|c|c|c|c|c|c|c|c|c|}
\hline \multirow{3}{*}{ REGIONS } & \multirow{3}{*}{$\begin{array}{l}\text { LOCAL } \\
\text { SEARCH }\end{array}$} & \multicolumn{2}{|c|}{$\begin{array}{l}\text { POSITION IN RANKING } \\
\text { CONSUMER }\end{array}$} & \multicolumn{6}{|c|}{ RESEARCH SAMPLE } \\
\hline & & & & M & $\mathrm{F}$ & $\mathrm{M}$ & $\mathrm{F}$ & M & $\mathrm{F}$ \\
\hline & & NATIONAL & STATE & & & & & & \\
\hline \multirow{3}{*}{ SOUTHEAST } & São Paulo - SP & 1 & 1 & \multirow{3}{*}{1260} & \multirow{3}{*}{1662} & \multirow{3}{*}{560} & \multirow{3}{*}{739} & \multirow{3}{*}{315} & \multirow{3}{*}{416} \\
\hline & $\begin{array}{c}\text { Rio de Janeiro - } \\
\text { RJ }\end{array}$ & 2 & 1 & & & & & & \\
\hline & $\begin{array}{c}\text { Belo Horizonte - } \\
\text { MG }\end{array}$ & 4 & 1 & & & & & & \\
\hline \multirow{3}{*}{ SOUTH } & Curitiba - PR & 5 & 1 & \multirow{3}{*}{1260} & \multirow{3}{*}{1662} & \multirow{3}{*}{560} & \multirow{3}{*}{739} & \multirow{3}{*}{315} & \multirow{3}{*}{416} \\
\hline & Porto Alegre - RS & 7 & 1 & & & & & & \\
\hline & Florianólpolis - SC & 27 & 1 & & & & & & \\
\hline \multirow{3}{*}{ NORTHEST } & Salvador - BA & 6 & 1 & \multirow{3}{*}{1260} & \multirow{3}{*}{1662} & \multirow{3}{*}{560} & \multirow{3}{*}{739} & \multirow{3}{*}{315} & \multirow{3}{*}{416} \\
\hline & Fortaleza - CE & 8 & 1 & & & & & & \\
\hline & Recife - PE & 10 & 1 & & & & & & \\
\hline \multirow{2}{*}{ MIDWEST } & Brasília - DF & 3 & 1 & \multirow{2}{*}{1260} & \multirow{2}{*}{1662} & \multirow{2}{*}{560} & \multirow{2}{*}{739} & \multirow{2}{*}{315} & \multirow{2}{*}{416} \\
\hline & Goiânia - GO & 9 & 1 & & & & & & \\
\hline \multirow{3}{*}{ NORTH } & Manaus - AM & 11 & 1 & \multirow{3}{*}{1260} & \multirow{3}{*}{1662} & & & & \\
\hline & Palmas - TO & 24 & 1 & & & 560 & 739 & 315 & 416 \\
\hline & Belém - PA & 13 & 1 & & & & & & \\
\hline & & & & 6300 & 8310 & 2800 & 3690 & 1575 & 2080 \\
\hline & & & TOTAL & & & & & & 55 \\
\hline
\end{tabular}

The current landscape of the measurements with the body scanner is shown in Table 4 . It can be observed that the sampling on the southeast region is well below the stipulated percentage error of $1 \%$ for both sexes and that measures of other regions of Brazil are still incipient issues for local logistics. The Senai CETIQT intend to finalize the measurements of other regions of Brazil in 2014.

Table 4. Current frame.

\begin{tabular}{|c|c|c|c|c|c|c|c|c|c|}
\hline \multicolumn{2}{|c|}{ Southest } & \multicolumn{2}{c|}{ North } & \multicolumn{2}{c|}{ Midwest } & \multicolumn{2}{c|}{ Brasil } \\
\hline M & F & M & F & M & F & M & F & M & F \\
\hline 2413 & 3809 & 112 & 207 & 10 & 41 & 63 & 286 & 2598 & 4343 \\
\hline
\end{tabular}

\subsection{Statistical Techniques}

The Multivariate Statistics consists of a set of statistical methods that apply in cases where several variables are measured simultaneously in each sample element (Mingoti. 2005 [2]).

One application is to explore the multivariable statistical data variability seeking a significant reduction in variables under study such that it does not compromise the overall variability of the data. In this study we used the exploratory techniques of data variability known as factor analysis and principal component analysis.

The factor analysis aims to describe the relationship between a large number $\boldsymbol{p}$ of variables in terms of a reduced number $\boldsymbol{m}$ of variables or factors unobservable. These unobservable variables and uncorrelated with each other represent a significant percentage of the variability of the original data and are related to the original variables through a linear model.

When the original variables replaced by their common factors must be interpreted through their numerical values called scores. 
The number of factors $\boldsymbol{m}<\boldsymbol{p}$ common that best represents the variability of the original data is defined according to criteria of interpretation of these factors and the variability structure of the linear model between the factors and the original variables standardized.

The Principal Component Analysis seeks to explain the structure of variance and covariance of a vector composed of $p$-random variables by constructing linear combinations of maximum variance uncorrelated called principal components. The Principal Component Analysis (PCA) allows a reduction in the number of variables making the phenomenon under study is represented simply without significant loss of information. In many cases this information can be combined in only two or three main components making interpretations easier as well as its graphical visualization.

The database is composed of 115 anthropometric measures of the body. To check the statistical methodology were selected initially by technician of Senai CETIQT 41 measures considered most significant for modeling clothing.

The first stage of the development of grid sizes was to validate the database. This stage is the cleaning of spurious data detection of typos or data transfer and disposal of individuals with missing data. This stage is very labor intensive because it depends on the concentration and the operator display and without it results may be compromised due to the failure in the database.

The second phase consisted of multivariate analysis itself. For this phase a program in MATLAB (Matrix Laboratory) is designed to perform statistical calculations and provide technical support to the analysis of modeling. The processing of the data by relying on interactive adjustments depending on the specific knowledge of anthropometry technicians and experts in statistics is not fully automated which requires time to run the program several times.

The program runs in two main routines. The first aims to eliminate variables with low correlation small communality (variance of the common factor given as a proportion of the total variance) and high variability attributed to random error. This routine makes the variance explained by the principal components closer to the total variance of data.

The second routine is based on principal component analysis in weighted variables and the individuals measured. The weights in the 41 selected variables were chosen in the first routine by modeling experts and placed in order of importance according to these experts. For the grid has a range of steady progression to the sizes of the bodies an interactive process between the program and the technical in statistics is required because the weights of the variables are adjusted every interaction.

In the grid of female bodies the weights of the individuals are specified depending on the biotype of each individual and the weight assigned to the individual equal to the percentage of biotype to which the individual belongs. In the grid of male bodies there different weights for individuals because these individuals are not classified according to a pre-defined biotype being assigned to each individual weight equal to 1 . In applying these statistical techniques to define the sizes of the bodies only two latent variables or unobservable were retained. One of the main components is retained sizes (heights) and the other body shapes (perimeter). Their scores were grouped according to similarities ensuring a strong association between individuals within the group and a weak association between individuals of different groups. Defined groups have been translated into its original variables defining this way the table size of the bodies.

Figure 2 shows flow charts that summarize the steps of development adopted for the preparation of table bodies.

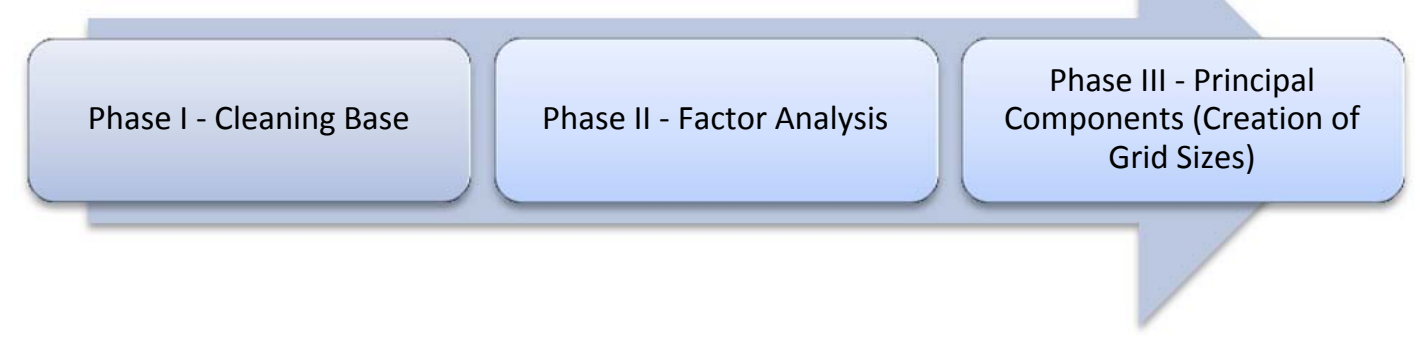

Fig 2. Flowchart overview of the process. 


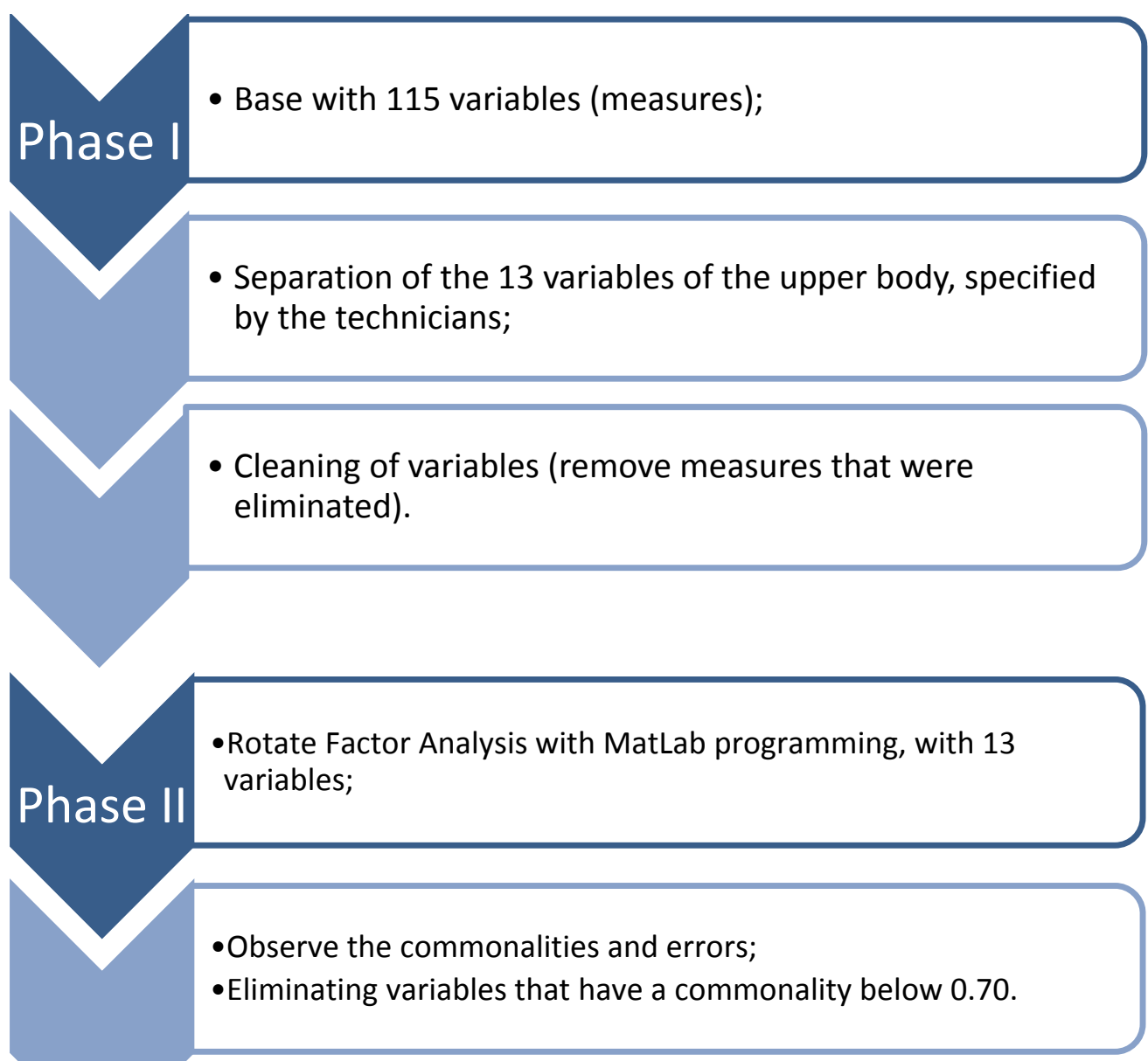

- Return a new factor analysis without the eliminated variables and observe how the commonalities and errors behave. After his explanation go to the third phase.

- Rotating schedule of Principal Component Programming with
Matlab;
- Checking the minimum and maximum limits of our principal
components and delimit amount of classes for each of the three
sizes of the bodies;
- Adjusting weights given by the technical modeling to reach the
best difference between sizes;
- Generating grid sizes.

Fig 3. Flowchart of stages of study. 


\section{Results}

In this paper, for reasons of space, we will present only the results obtained for female bodies.

To ensure that the anthropometric data can be analyzed by multivariate statistical techniques, in this case the factor analysis, some care must be taken. For this study it was found that:

1) all study variables follow a univariate normal distribution;

2) the basis used follows a multivariate normal distribution;

3 ) the Bartlett's test to the significance level of $5 \%$ rejected the null hypothesis of correlation matrix identity;

4) Test Kaiser-Meyer-Olkin (KMO) showed a value> 0.8 .

The study base consisted of 41 body variables of 3534 female subjects. Table 5 presents the variables studied.

Table 5. Study variables SizeBR.

\begin{tabular}{|c|c|c|c|c|c|}
\hline Order & Variable & Order & Variable & Order & Variable \\
\hline 1 & 407 Chest/bust girth & 15 & 317 Center-trunck length & 29 & 320 Back Crotch lenght - stand up \\
\hline 2 & 416 Hip girth/low hip & 16 & 003 Head girth & 30 & 305 Shoulder length \\
\hline 3 & 409 Waist girth & 17 & 408 Underbust girth & 31 & 008 Elbow length \\
\hline 4 & 002 Height & 18 & 406 High chest girth & 32 & 402 Arm Scye girth \\
\hline 5 & 113 Outside leg length & 19 & 412 Low waist girth & 33 & 010 Arm girth $-90^{\circ}$ \\
\hline 6 & 106 Inside leg height & 20 & 414 High hip girth & 34 & 011 Elbow girth $-90^{\circ}$ \\
\hline 7 & 117 Waist to crotch height & 21 & $\begin{array}{l}118 \text { Waist - hip height - right } \\
\text { side }\end{array}$ & 35 & 405 Wrist girth -right side \\
\hline 8 & $\begin{array}{l}302 \text { Neck to waist contour } \\
\text { back }\end{array}$ & 22 & 116 Waist - knee height & 36 & 012 Hand closet girth \\
\hline 9 & $\begin{array}{l}301 \text { Center front neck to } \\
\text { waist }\end{array}$ & 23 & 419 Thigh girh & 37 & 325 Across back contour \\
\hline 10 & $\begin{array}{l}313 \text { Neck to waist length - } \\
\text { right side }\end{array}$ & 24 & 421 Knee girth & 38 & 326 Scy to Scy length - front side \\
\hline 11 & $\begin{array}{l}324 \text { Shoulder to shoulder } \\
\text { length - back side }\end{array}$ & 25 & 423 Calf girh & 39 & $\begin{array}{l}314 \text { Neck to underbust lengty - } \\
\text { right side }\end{array}$ \\
\hline 12 & 009 Arm length $-90^{\circ}$ & 26 & 426 Low ankle girth & 40 & $\begin{array}{l}312 \text { Neck to bust point length - } \\
\text { right side }\end{array}$ \\
\hline 13 & 300 Neck height & 27 & 318 Crotch lenght - stand up & 41 & 204 Bust point to Bust point \\
\hline 14 & $\begin{array}{l}104 \text { Long shoulder height - } \\
\text { right side }\end{array}$ & 28 & $\begin{array}{l}319 \text { Front Crotch lenght - } \\
\text { stand up }\end{array}$ & & \\
\hline
\end{tabular}

With the purpose of eliminating low correlation variables, and possibly also with low variance explained common, factor analysis was performed on the covariance matrix of original data.

The factor analysis presented in Table 6, indicates that eight factors together explain approximately $77.87 \%$ of the variance of the original data matrix. However, in this first analysis, we chose to evaluate only 5 factors.

Table 6. Variance Explained by common factors.

\begin{tabular}{|c|c|c|c|}
\hline \multicolumn{4}{|c|}{ Common Factors X Variance Explained } \\
\hline Factor & autovalue & \%Var expl & \%total Var exp \\
\hline 1 & 15.49 & 37.77 & 37.77 \\
\hline 2 & 5.69 & 13.88 & 51.65 \\
\hline 3 & 4.25 & 10.37 & 62.02 \\
\hline 4 & 1.63 & 3.97 & 65.99 \\
\hline 5 & 1.49 & 3.64 & 69.63 \\
\hline 6 & 1.19 & 2.89 & 72.52 \\
\hline 7 & 1.16 & 2.84 & 75.35 \\
\hline 8 & 1.03 & 2.51 & 77.87 \\
\hline 9 & 0.97 & 2.37 & 80.24 \\
\hline 39 & 0.04 & 0.09 & 9977 \\
\hline 40 & 0.05 & 0.12 & 99.89 \\
\hline 41 & 0.05 & 0.11 & 100.00 \\
\hline
\end{tabular}


The method of principal components was used to estimate the loads of the five factors retained. From Table 7 it can be observed in specific commonalities and the variances (Var. error), the variables orders $12,16,21,26,31,32,34,35,36,37,38,39,40$ and 41 clashes with the model and must be removed.

Table 7. Estimation of factors.

\begin{tabular}{|c|c|c|c|c|c|c|c|c|}
\hline Order & Variable & Load F1 & Load F2 & Load F3 & Load F4 & Load F5 & commonalities & $\begin{array}{l}\text { Var. } \\
\text { error }\end{array}$ \\
\hline 1 & 407 Chest/bust girth & 0.92 & -0.22 & 0.04 & 0.02 & -0.01 & 0.90 & 0.10 \\
\hline 2 & 416 Hip girth/low hip & 0.90 & -0.12 & -0.13 & 0.05 & 0.14 & 0.87 & 0.13 \\
\hline 3 & 409 Waist girth & 0.89 & -0.28 & 0.18 & 0.03 & 0.09 & 0.91 & 0.09 \\
\hline 4 & 002 Height & 0.29 & 0.90 & 0.08 & -0.07 & -0.01 & 0.91 & 0.09 \\
\hline 5 & 113 Outside leg length & 0.28 & 0.88 & -0.27 & 0.11 & -0.09 & 0.94 & 0.06 \\
\hline 6 & 106 Inside leg height & 0.08 & 0.82 & 0.24 & 0.37 & -0.10 & 0.88 & 0.12 \\
\hline 7 & 117 Waist to crotch height & 0.38 & 0.16 & -0.73 & -0.13 & -0.04 & 0.72 & 0.28 \\
\hline 8 & 302 Neck to waist contour back & 0.27 & 0.30 & 0.68 & -0.38 & 0.11 & 0.78 & 0.22 \\
\hline 9 & 301 Center front neck to waist & 0.45 & 0.12 & 0.59 & -0.44 & 0.09 & 0.77 & 0.23 \\
\hline 10 & 313 Neck to waist length - right side & 0.51 & 0.15 & 0.63 & -0.44 & 0.03 & 0.87 & 0.13 \\
\hline 11 & 324 Shoulder to shoulder length - back side & 0.56 & -0.13 & 0.07 & 0.05 & -0.68 & 0.80 & 0.20 \\
\hline 12 & 009 Arm length $-90^{\circ}$ & 0.32 & 0.58 & 0.10 & 0.18 & 0.07 & 0.49 & 0.51 \\
\hline 13 & 300 Neck height & 0.37 & 0.76 & 0.43 & -0.03 & 0.00 & 0.90 & 0.10 \\
\hline 14 & 104 Long shoulder height - right side & 0.31 & 0.91 & 0.06 & -0.08 & 0.00 & 0.94 & 0.06 \\
\hline 15 & 317 Center-trunck length & 0.73 & 0.16 & -0.11 & -0.43 & 0.13 & 0.78 & 0.22 \\
\hline 16 & 003 Head girth & 0.35 & 0.18 & 0.01 & 0.17 & -0.06 & 0.19 & 0.81 \\
\hline 17 & 408 Underbust girth & 0.90 & -0.23 & 0.02 & 0.05 & 0.00 & 0.87 & 0.13 \\
\hline 18 & 406 High chest girth & 0.92 & -0.20 & 0.04 & 0.03 & -0.08 & 0.89 & 0.11 \\
\hline 19 & 412 Low waist girth & 0.92 & -0.24 & 0.03 & 0.04 & 0.11 & 0.92 & 0.08 \\
\hline 20 & 414 High hip girth & 0.93 & -0.23 & -0.04 & 0.04 & 0.12 & 0.93 & 0.07 \\
\hline 21 & 118 Waist - hip height - right side & -0.31 & 0.40 & -0.51 & -0.14 & -0.03 & 0.54 & 0.46 \\
\hline 22 & 116 Waist - knee height & 0.29 & 0.65 & -0.58 & -0.07 & -0.08 & 0.85 & 0.15 \\
\hline 23 & 419 Thigh girh & 0.77 & -0.01 & 0.05 & 0.36 & 0.10 & 0.73 & 0.27 \\
\hline 24 & 421 Knee girth & 0.76 & 0.03 & 0.04 & 0.31 & 0.13 & 0.70 & 0.30 \\
\hline 25 & 423 Calf girh & 0.80 & -0.05 & 0.02 & 0.25 & 0.10 & 0.71 & 0.29 \\
\hline 26 & 426 Low ankle girth & 0.48 & 0.23 & 0.01 & 0.07 & -0.07 & 0.30 & 0.70 \\
\hline 27 & 318 Crotch lenght - stand up & 0.65 & 0.02 & -0.70 & -0.22 & 0.05 & 0.96 & 0.04 \\
\hline 28 & 319 Front Crotch lenght - stand up & 0.69 & 0.02 & -0.63 & -0.14 & 0.03 & 0.90 & 0.10 \\
\hline 29 & 320 Back Crotch lenght - stand up & 0.57 & 0.03 & -0.72 & -0.27 & 0.06 & 0.91 & 0.09 \\
\hline 30 & 305 Shoulder length & 0.19 & -0.03 & 0.10 & -0.06 & -0.82 & 0.73 & 0.27 \\
\hline 31 & 008 Elbow length & 0.29 & 0.53 & 0.09 & 0.14 & 0.10 & 0.40 & 0.60 \\
\hline 32 & 402 Arm Scye girth & 0.35 & -0.06 & 0.11 & 0.14 & 0.11 & 0.17 & 0.83 \\
\hline 33 & 010 Arm girth $-90^{\circ}$ & 0.79 & -0.22 & -0.01 & 0.12 & 0.09 & 0.70 & 0.30 \\
\hline 34 & 011 Elbow girth $-90^{\circ}$ & 0.65 & -0.02 & 0.03 & 0.16 & 0.03 & 0.45 & 0.55 \\
\hline 35 & 405 Wrist girth -right side & 0.71 & -0.05 & 0.07 & 0.13 & 0.10 & 0.53 & 0.47 \\
\hline 36 & 012 Hand closet girth & 0.49 & 0.15 & 0.11 & 0.11 & -0.03 & 0.29 & 0.71 \\
\hline 37 & 325 Across back contour & 0.69 & -0.17 & 0.10 & 0.05 & -0.30 & 0.60 & 0.40 \\
\hline 38 & 326 Scy to Scy length - front side & 0.59 & -0.09 & -0.05 & -0.16 & -0.17 & 0.41 & 0.59 \\
\hline 39 & 314 Neck to underbust lengty - right side & 0.52 & -0.21 & 0.16 & -0.14 & -0.04 & 0.36 & 0.64 \\
\hline 40 & 312 Neck to bust point length - right side & 0.74 & -0.15 & 0.13 & -0.18 & -0.04 & 0.61 & 0.39 \\
\hline 41 & 204 Bust point to Bust point & 0.63 & -0.12 & 0.09 & -0.05 & -0.10 & 0.43 & 0.57 \\
\hline
\end{tabular}

It is also observed that it is not possible to secure an interpretation of the first five factors. For example, the values highlighted in the load of the first factor in the variables have high values relating to the diameters and lengths. Moreover, the fourth factor loads do not allow the interpretation presented by low values of all the variables.

A new factor analysis was performed eliminating variables underperforming. In this analysis, the first five factors have values above 1 - see Table 8 , representing a total of $86.44 \%$ of the total variance $69.63 \%$ against the previous model. In this way, it is concluded that the removal of the three variables was right. 
Table 8. Variance Explained by common factors.

\begin{tabular}{|l|l|l|l|}
\hline \multicolumn{4}{|c|}{ Common Factors $\times$ Variance Explained } \\
\hline \multicolumn{1}{|c|}{ Factor } & \multicolumn{1}{|c|}{ Autovalue } & \% Var expl & \%total Var expl \\
\hline 1 & 11.76 & 43.55 & 43.55 \\
\hline 2 & 4.83 & 17.88 & 61.43 \\
\hline 3 & 3.87 & 14.34 & 75.78 \\
\hline 4 & 1.50 & 5.57 & 81.34 \\
\hline 5 & 1.38 & 5.10 & 86.44 \\
\hline 6 & 0.82 & 3.06 & 89.50 \\
\hline 7 & $\ldots$ & $\ldots$. & $\ldots$ \\
\hline 8 & 0.06 & 0.21 & 99.67 \\
\hline 9 & 0.04 & 0.16 & 99.82 \\
\hline 10 & 0.05 & 0.18 & 100.00 \\
\hline
\end{tabular}

The factor loadings of the first five principal components are presented in Table 9. It can be seen that the commonalities are greater than 0.70 and that the variances are shown specific low, which again shows that this model of 27 variables is greater than 41 variables.

Table 9. Factor loadings.

\begin{tabular}{|c|c|c|c|c|c|c|c|c|}
\hline Order & Variable & Load F1 & Load F2 & Load F3 & Load F4 & Load F5 & Commonalities & $\begin{array}{l}\text { Var. } \\
\text { error }\end{array}$ \\
\hline 1 & 407 Chest/bust girth & 0.90 & 0.21 & 0.13 & -0.04 & 0.01 & 0.88 & 0.12 \\
\hline 2 & 416 Hip girth/low hip & 0.93 & 0.15 & -0.02 & -0.04 & 0.11 & 0.89 & 0.11 \\
\hline 3 & 409 Waist girth & 0.87 & 0.25 & 0.27 & 0.00 & 0.08 & 0.90 & 0.10 \\
\hline 4 & 002 Height & 0.29 & -0.91 & -0.05 & 0.03 & 0.00 & 0.91 & 0.09 \\
\hline 5 & 113 Outside leg length & 0.30 & -0.82 & -0.41 & -0.18 & 0.00 & 0.98 & 0.02 \\
\hline 6 & 106 Inside leg height & 0.06 & -0.85 & 0.08 & -0.46 & 0.08 & 0.95 & 0.05 \\
\hline 7 & 117 Waist to crotch height & 0.44 & -0.05 & -0.72 & 0.11 & -0.09 & 0.73 & 0.27 \\
\hline 8 & 302 Neck to waist contour back & 0.24 & -0.43 & 0.67 & 0.37 & -0.01 & 0.83 & 0.17 \\
\hline 9 & 301 Center front neck to waist & 0.43 & -0.23 & 0.62 & 0.39 & -0.05 & 0.77 & 0.23 \\
\hline 10 & 313 Neck to waist length - right side & 0.47 & -0.28 & 0.65 & 0.38 & -0.09 & 0.87 & 0.13 \\
\hline 11 & 324 Shoulder to shoulder length - back & 0.54 & 0.11 & 0.13 & -0.21 & -0.67 & 0.82 & 0.18 \\
\hline 13 & 300 Neck height & 0.35 & -0.84 & 0.31 & -0.01 & 0.02 & 0.91 & 0.09 \\
\hline 14 & 104 Long shoulder height - right side & 0.32 & -0.92 & -0.07 & 0.03 & 0.02 & 0.95 & 0.05 \\
\hline 15 & 317 Center-trunck length & 0.76 & -0.15 & -0.05 & 0.43 & -0.04 & 0.78 & 0.22 \\
\hline 17 & 408 Underbust girth & 0.90 & 0.22 & 0.12 & -0.04 & 0.01 & 0.86 & 0.14 \\
\hline 18 & 406 High chest girth & 0.90 & 0.18 & 0.13 & -0.05 & -0.04 & 0.87 & 0.13 \\
\hline 19 & 412 Low waist girth & 0.92 & 0.24 & 0.13 & -0.02 & 0.09 & 0.93 & 0.07 \\
\hline 20 & 414 High hip girth & 0.94 & 0.23 & 0.07 & -0.02 & 0.10 & 0.94 & 0.06 \\
\hline 22 & 116 Waist - knee height & 0.33 & -0.55 & -0.66 & 0.03 & -0.05 & 0.86 & 0.14 \\
\hline 23 & 419 Thigh girh & 0.78 & 0.02 & 0.13 & -0.41 & 0.17 & 0.83 & 0.17 \\
\hline 24 & 421 Knee girth & 0.77 & -0.01 & 0.12 & -0.34 & 0.16 & 0.75 & 0.25 \\
\hline 25 & 423 Calf girh & 0.81 & 0.07 & 0.11 & -0.28 & 0.12 & 0.76 & 0.24 \\
\hline 27 & 318 Crotch lenght - stand up & 0.71 & 0.09 & -0.64 & 0.24 & -0.05 & 0.97 & 0.03 \\
\hline 28 & 319 Front Crotch lenght - stand up & 0.74 & 0.08 & -0.58 & 0.16 & -0.03 & 0.92 & 0.08 \\
\hline 29 & 320 Back Crotch lenght - stand up & 0.63 & 0.09 & -0.65 & 0.29 & -0.06 & 0.91 & 0.09 \\
\hline 30 & 305 Shoulder length & 0.18 & -0.01 & 0.12 & -0.21 & -0.88 & 0.87 & 0.13 \\
\hline 33 & 010 Arm girth $-90^{\circ}$ & 0.79 & 0.23 & 0.09 & -0.09 & 0.08 & 0.70 & 0.30 \\
\hline
\end{tabular}

Table 9 gives a highlight only on the factors not rotated. In the analysis of loads of factors, the variable Crotch Length-stand up can be interpreted by loads of factors 1 and 3 and the same happened with the variable Back Crotch Length-stand up. Thus, the array of factors was rotated to ensure a common understanding of the factors insurance.

Table 10 shows the rotated factors. You can check the charges highlighted that factor 1 represents the variables related to the circumferences, factor 2 represents the heights above the ground, the third factor is the relative heights, the factor 4 and 5 represent relative lengths. 
Table 10. Rotated factor loadings.

\begin{tabular}{|l|l|l|l|l|l|l|}
\hline Order & Variable & Load F1 & Load F2 & Load F3 & Load F4 & Load F5 \\
\hline 1 & 407 Chest/bust girth & 0.86 & 0.04 & -0.25 & 0.22 & -0.13 \\
\hline 2 & 416 Hip girth/low hip & 0.86 & -0.04 & -0.36 & 0.13 & -0.03 \\
\hline 3 & 409 Waist girth & 0.88 & 0.11 & -0.14 & 0.30 & -0.07 \\
\hline 4 & 002 Height & 0.00 & -0.89 & -0.18 & 0.30 & 0.00 \\
\hline 5 & 113 Outside leg length & 0.03 & -0.92 & -0.35 & -0.08 & -0.03 \\
\hline 6 & 106 Inside leg height & 0.02 & -0.94 & 0.27 & -0.04 & -0.02 \\
\hline 7 & 117 Waist to crotch height & 0.16 & -0.16 & -0.79 & -0.23 & -0.05 \\
\hline 8 & 302 Neck to waist contour back & 0.10 & -0.25 & 0.22 & 0.84 & 0.00 \\
\hline 9 & 301 Center front neck to waist & 0.29 & -0.10 & 0.09 & 0.81 & -0.06 \\
\hline 10 & 313 Neck to waist length - right side & 0.31 & -0.15 & 0.10 & 0.85 & -0.11 \\
\hline 11 & 324 Shoulder to shoulder length - back & 0.44 & 0.00 & -0.11 & 0.09 & -0.78 \\
\hline 13 & 300 Neck height & 0.15 & -0.81 & 0.10 & 0.48 & -0.03 \\
\hline 14 & 104 Long shoulder height - right side & 0.02 & -0.91 & -0.20 & 0.30 & 0.02 \\
\hline 15 & 317 Center-trunck length & 0.45 & -0.14 & -0.56 & 0.50 & -0.02 \\
\hline 17 & 408 Underbust girth & 0.86 & 0.05 & -0.25 & 0.20 & -0.13 \\
\hline 18 & 406 High chest girth & 0.85 & 0.02 & -0.25 & 0.21 & -0.18 \\
\hline 19 & 412 Low waist girth & 0.90 & 0.07 & -0.26 & 0.22 & -0.05 \\
\hline 20 & 414 High hip girth & 0.90 & 0.05 & -0.31 & 0.18 & -0.05 \\
\hline 22 & 116 Waist - knee height & -0.01 & -0.63 & -0.66 & -0.15 & -0.01 \\
\hline 23 & 419 Thigh girh & 0.88 & -0.24 & 0.01 & -0.05 & -0.05 \\
\hline 24 & 421 Knee girth & 0.83 & -0.24 & -0.03 & 0.01 & -0.03 \\
\hline 25 & 423 Calf girh & 0.85 & -0.15 & -0.09 & 0.04 & -0.07 \\
\hline 27 & 318 Crotch lenght - stand up & 0.41 & -0.03 & -0.89 & -0.07 & -0.02 \\
\hline 28 & 319 Front Crotch lenght - stand up & 0.48 & -0.06 & -0.82 & -0.08 & -0.04 \\
\hline 29 & 320 Back Crotch lenght - stand up & 0.32 & 0.00 & -0.90 & -0.06 & -0.01 \\
\hline 30 & 305 Shoulder length & 0.05 & -0.03 & 0.00 & 0.05 & -0.93 \\
\hline 33 & 010 Arm girth - 90 & 0.80 & 0.06 & -0.20 & 0.11 & -0.06 \\
\hline
\end{tabular}

In this way, factors 1 and 2 relate to a large part of the 27 variables selected before and together explain $61.43 \%$ of total variance, as shown in Table 8 was selected for continuing the task of obtaining the grid size.

The factor analysis allowed to select important variables for the study, as well as the number of factors and their interpretations.

The next develop a principal component analysis with selected variables in the factor analysis. The analysis was performed as adapted from Veitch 2007 [4].

The component 1 (CP1) is interpreted as the perimeter body and the component 2 (CP2) such as length, i.e. CP1 represents CP2 body shape and size.

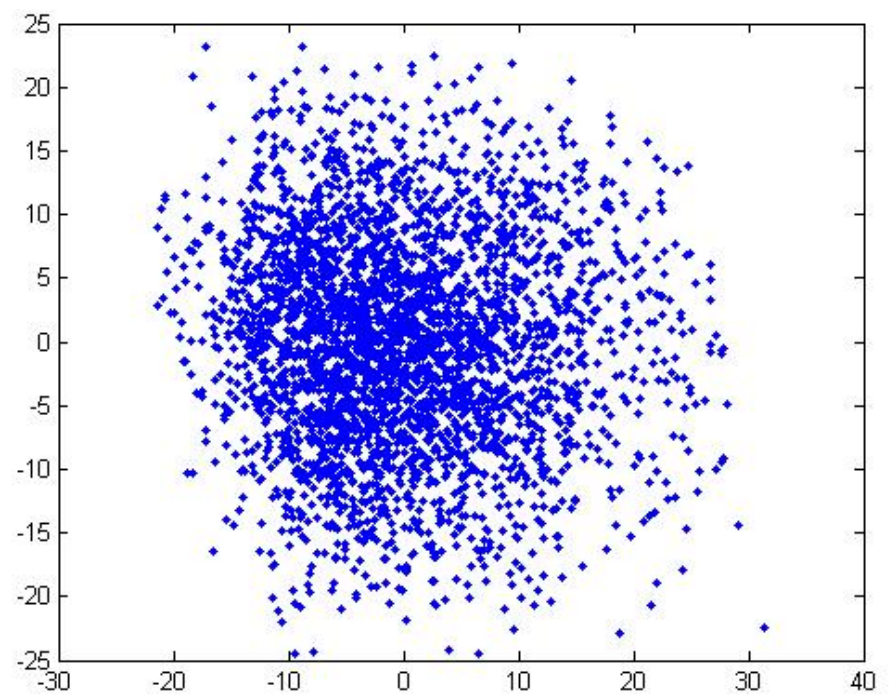

Fig 4. Component $1 \times$ Component 2. 
Figure 4 shows the distribution of factor scores on components 1 and 2 in each of the 3534 individuals measured. As the component 1 represents the shape of the body, their scores were divided into three regions called High, Medium and Low which can be associated with athletic bodies, Normal and Special, according to ABNT NBR 10060:2012. Similarly, the scores in the second component were divided into fourteen classes, i.e. for each body type High $(\mathrm{H})$, Medium $(\mathrm{M})$ or Low (L) there are 14 bands of sizes forming the pairs $\mathrm{H} 1, \mathrm{H} 2, \mathrm{H} 3, \mathrm{H} 4, \mathrm{H} 5, \mathrm{H} 6, \mathrm{H} 7, \mathrm{H} 8, \mathrm{H} 9, \mathrm{H} 10, \mathrm{H} 11, \mathrm{H} 12$, $\mathrm{H} 13$ and H14. The same applies to $\mathrm{M}$ and L, totaling 42 standards bodies.

The scores in the component 2 were assigned such that the central strip presents $66 \%$ of individuals in the population and had as the medium center 50th percentile. The other tracks, High $(\mathrm{H})$ and Low $(L)$, divided the remaining $34 \%$ of the population equitably, taking to heart the average 50th percentile.

The scores in component 1 were divided to present a constant value of $4 \mathrm{~cm}$ in variable difference Chest/bust girth, in each of the standardized forms bodies.

After the distribution of scores on a grid of size or Clusters, you must process the calculation processing of the centroids of the scores of individuals on approximate measures on the original variables. These measures represent approximate measures for each of the bodies developed by crossing scores on components 1 and 2 . Table 11 presents the results found.

The method allows to calculate the percentage of individuals that falls in each of the bodies determined standards. As an example, for the sample, Figure 5 shows that the standard body Medium body 4 is $9.3 \%$ quota studied.

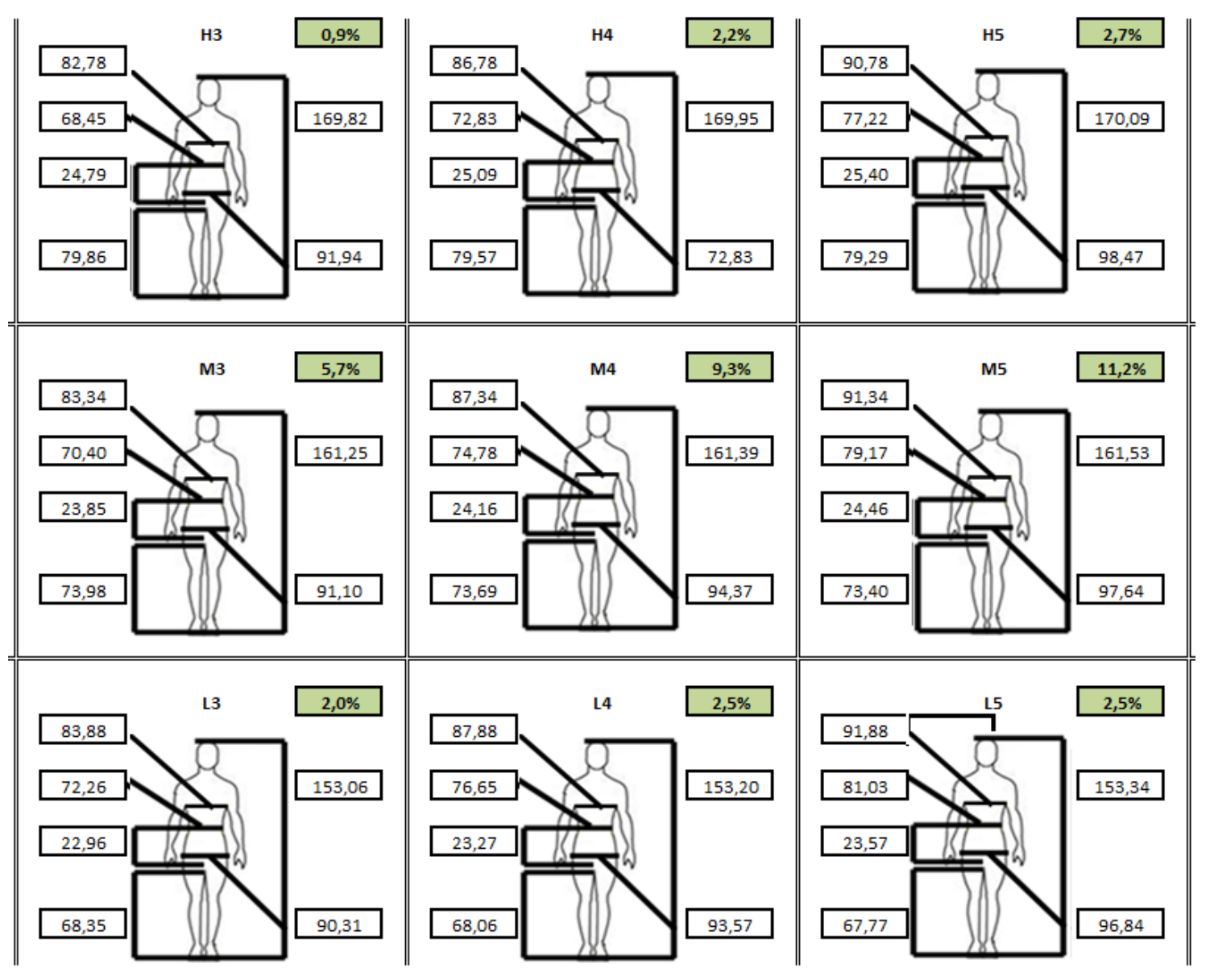

Fig 5. Extract of body shape.

The grid sizes shown in Table 11 does not include all individuals in the sample, because some have been removed, or display values outside the three deviations or adequacy of the components in the division into classes. Table 12 shows the percentage achieved in the study. 
Table 11. Outcome superior measures female - Southeast - Sizing systems.

\begin{tabular}{|c|c|c|c|c|c|c|c|}
\hline & $\begin{array}{c}\text { Chest/bust } \\
\text { girth }\end{array}$ & $\begin{array}{l}\text { Hip girth/low } \\
\text { hip }\end{array}$ & Waist girth & Height & Outside leg length & $\begin{array}{l}\text { Inside leg } \\
\text { height }\end{array}$ & $\begin{array}{c}\text { Waist to crotch } \\
\text { height }\end{array}$ \\
\hline H1 & 74.8 & 85.4 & 59.7 & 169.5 & 104.6 & 80.4 & 24.2 \\
\hline M1 & 75.3 & 84.6 & 61.6 & 161.0 & 97.8 & 74.6 & 23.2 \\
\hline $\mathbf{L 1}$ & 75.9 & 83.8 & 63.5 & 152.8 & 91.3 & 68.9 & 22.4 \\
\hline H2 & 78.8 & 88.7 & 64.1 & 169.7 & 104.6 & 80.2 & 24.5 \\
\hline M2 & 79.3 & 87.8 & 66.0 & 161.1 & 97.8 & 74.3 & 23.5 \\
\hline $\mathbf{L 2}$ & 79.9 & 87.0 & 67.9 & 152.9 & 91.3 & 68.6 & 22.7 \\
\hline H3 & 82.8 & 91.9 & 68.4 & 169.8 & 104.6 & 79.9 & 24.8 \\
\hline M3 & 83.3 & 91.1 & 70.4 & 161.3 & 97.8 & 74.0 & 23.9 \\
\hline L3 & 83.9 & 90.3 & 72.3 & 153.1 & 91.3 & 68.3 & 23.0 \\
\hline H4 & 86.8 & 95.2 & 72.8 & 170.0 & 104.6 & 79.6 & 25.1 \\
\hline M4 & 87.3 & 94.4 & 74.8 & 161.4 & 97.8 & 73.7 & 24.2 \\
\hline $\mathrm{L} 4$ & 87.9 & 93.6 & 76.6 & 153.2 & 91.3 & 68.1 & 23.3 \\
\hline H5 & 90.8 & 98.5 & 77.2 & 170.1 & 104.6 & 79.3 & 25.4 \\
\hline M5 & 91.3 & 97.6 & 79.2 & 161.5 & 97.8 & 73.4 & 24.5 \\
\hline L5 & 91.9 & 96.8 & 81.0 & 153.3 & 91.3 & 67.8 & 23.6 \\
\hline " H6 & 94.8 & 101.7 & 81.6 & $\begin{array}{l}170.2 \\
\end{array}$ & 104.7 & 79.0 & 25.7 \\
\hline M6 & 95.3 & 100.9 & 83.6 & 161.7 & 97.9 & 73.1 & 24.8 \\
\hline L6 & 95.9 & 100.1 & 85.4 & 153.5 & 91.3 & 67.5 & 23.9 \\
\hline H7 & 98.8 & 105.0 & 86.0 & 170.4 & 104.7 & 78.7 & 26.0 \\
\hline M7 & 99.3 & 104.2 & 87.9 & 161.8 & 97.9 & 72.8 & 25.1 \\
\hline L7 & 99.9 & 103.4 & 89.8 & 153.6 & 91.4 & 67.2 & 24.2 \\
\hline "H8 & 102.8 & "108.3 & 90.4 & 170.5 & 104.7 & 78.4 & 26.3 \\
\hline M8 & 103.3 & 107.4 & 92.3 & 161.9 & 97.9 & 72.5 & 25.4 \\
\hline L8 & 103.9 & 106.6 & 94.2 & 153.8 & 91.4 & 66.9 & 24.5 \\
\hline H9 & 106.8 & 1111.5 & 94.8 & 170.6 & 104.7 & 78.1 & 26.6 \\
\hline M9 & 107.3 & 110.7 & 96.7 & 162.1 & 97.9 & 72.3 & 25.7 \\
\hline L9 & 107.9 & 109.9 & 98.6 & 153.9 & 91.4 & 66.6 & 24.8 \\
\hline "H10 & 110.8 & 114.8 & 999.1 & $\begin{array}{l}170.8 \\
\end{array}$ & $\begin{array}{l}104.7 \\
\end{array}$ & 77.8 & 26.9 \\
\hline M10 & 111.4 & 114.0 & 101.1 & 162.2 & 97.9 & 72.0 & 26.0 \\
\hline L10 & 111.9 & 113.2 & 103.0 & 154.0 & 91.4 & 66.3 & 25.1 \\
\hline H11 & 114.8 & 118.1 & 103.5 & 170.9 & 104.7 & 77.6 & 27.2 \\
\hline M11 & 115.4 & 117.2 & 105.5 & 162.4 & 97.9 & 71.7 & 26.3 \\
\hline L11 & 115.9 & 116.4 & 107.3 & 154.2 & 91.4 & 66.0 & 25.4 \\
\hline "H12 & 118.8 & 121.3 & 107.9 & 171.1 & 104.7 & 77.3 & 27.5 \\
\hline M12 & 119.4 & 120.5 & 109.9 & 162.5 & 97.9 & 71.4 & 26.6 \\
\hline L12 & 119.9 & 119.7 & 111.7 & 154.3 & 91.4 & 65.8 & 25.7 \\
\hline H13 & 122.8 & 124.6 & 112.3 & 171.2 & 104.7 & $\begin{array}{l}77.0 \\
\end{array}$ & 27.8 \\
\hline M13 & 123.4 & 123.8 & 114.2 & 162.6 & 97.9 & 71.1 & 26.9 \\
\hline L13 & 123.9 & 123.0 & 116.1 & 154.4 & 91.4 & 65.5 & 26.0 \\
\hline H14 & 126.8 & 127.9 & 116.7 & 171.3 & 104.8 & 76.7 & 28.1 \\
\hline M14 & 127.4 & 127.0 & 118.6 & 162.8 & 98.0 & 70.8 & 27.2 \\
\hline L14 & 127.9 & 126.2 & 120.5 & 154.6 & 91.4 & 65.2 & 26.3 \\
\hline
\end{tabular}

Table 12: Percentage Distribution of the sample on the grid sizes.

\begin{tabular}{|c|c|c|c|c|c|c|c|c|c|c|c|c|c|c|}
\hline L1 & L2 & L3 & L4 & $\mathbf{L 5}$ & L6 & L7 & L8 & L9 & L10 & L11 & L12 & L13 & L14 & \\
\hline $0.2 \%$ & $0.4 \%$ & $2.0 \%$ & $2.5 \%$ & $2.5 \%$ & $2.3 \%$ & $1.7 \%$ & $1.8 \%$ & $1.1 \%$ & $0.8 \%$ & $0.3 \%$ & $0.2 \%$ & $0.0 \%$ & $0.0 \%$ & $15.9 \%$ \\
\hline M1 & M2 & M3 & M4 & M5 & M6 & M7 & M8 & M9 & M10 & M11 & M12 & M13 & M14 & \\
\hline $0.5 \%$ & $1.8 \%$ & $5.7 \%$ & $9.3 \%$ & $11.2 \%$ & $9.7 \%$ & $7.9 \%$ & $5.8 \%$ & $3.5 \%$ & $2.6 \%$ & $1.0 \%$ & $0.9 \%$ & $0.3 \%$ & $0.0 \%$ & $60.3 \%$ \\
\hline $\mathrm{H} 1$ & $\mathrm{H} 2$ & $\mathrm{H3}$ & $\mathrm{H} 4$ & $\mathrm{H} 5$ & $\mathrm{H} 6$ & $\mathrm{H7}$ & $\mathrm{H8}$ & H9 & $\mathrm{H} 10$ & $\mathrm{H} 11$ & $\mathrm{H} 12$ & $\mathrm{H} 13$ & $\mathrm{H} 14$ & \\
\hline $0.1 \%$ & $0.3 \%$ & $0.9 \%$ & $2.2 \%$ & $2.7 \%$ & $2.4 \%$ & $2.0 \%$ & $1.7 \%$ & $1.4 \%$ & $0.5 \%$ & $0.4 \%$ & $0.3 \%$ & $0.1 \%$ & $0.0 \%$ & $15.0 \%$ \\
\hline
\end{tabular}




\section{Conclusion}

This work was dedicated to the presentation of the methodology applied in the definition of female upper bodies of southeastern Brazil. These results are part of a large nationwide study - SizeBR created, developed and applied by Senai CETIQT, with the goal of establishing standards bodies of the Brazilian population, segmented by five regions, to meet those interested in modeling clothing in general such as: pants, Dresses, Overalls, Shirt, jacket or jackets.

To set the grid sizes of bodies was developed a methodology which applies multivariate statistical methods.

The anthropometric data base of individuals was treated and suitability tests were carried out to justify the application of the methodology adopted.

The factorial analysis ruled out fourteen variables that, although they were pointed by the technician in modeling, were not in agreement with the rest of the group.

There were retained five main components, two of which were part of the calculations for the effective definition of the grid sizes.

The component 1 is associated to the bodies while the component 2 is associated to size.

It was sought on the basis of certain weights to the variables under study, an order of preference for the same modeling of upper garments. This order was maintained in the study, required adjustments in the weight values for obtaining a constant value of $4 \mathrm{~cm}$ at the most important variable, in this case, the Chest/bust girth.

The obtained grid crosses three classes of forms against fourteen of sizes, totaling 42 standard bodies and $91.2 \%$ of the population framework.

\section{References}

1. Lee, J.Y., Istook, C. L., Nam, Y. J. and Park, S. M., Comparison of body shape between USA and Korean women, International Journal of Clothing Science and Technology, Vol. 19, No. 5, pp. 374-391, 2007.

2. Mingot. S. A., Análise de Dados Através de Métodos de Estatística Multivariada - Uma Abordagem Aplicada, Belo Horizonte, Editora UFMG, 2005.

3. Thompson, S. K., Sampling, John wiley \& Sons, 3rd ed, 2012.

4. Veitch, D., Veitch, L., Henneberg, M., Sizing for the Clothing Industry Using Principal Component Analysis - An Australian Example, Journal of ASTM International, Vol. 4, No. 3, 2007. 